\title{
Outcome of Transient Hypogastric Artery Balloon Occlusion with Cesarean Hysterectomy in Abnormal Adherent Placenta: Case Series
}

\author{
Keerati Hongsakul, M.D. ${ }^{1}$, Jitwadee Suwanlee, M.D. ${ }^{1}$, Sorracha Rookkapan, M.D. ${ }^{1}$, \\ Kittipitch Bannangkoon, M.D. ${ }^{1}$, Ninlapa Pruksanusak, M.D. ${ }^{2}$, Yuthasak Suphasynth, M.D. ${ }^{2}$, \\ Shafie Abdullah, M.D. ${ }^{3}$, Chandran Nadarajan, M.D. ${ }^{3}$
}

'Department of Radiology, 'Department of Obstetrics and Gynecology, Faculty of Medicine, Prince of Songkla University, Hat Yai, Songkhla 90110, Thailand.

${ }^{3}$ Department of Radiology, School of Medical Sciences, Health Campus, Universiti Sains Malaysia, Kubang Kerian, Kelantan 16150, Malaysia.

Received 1 March 2019 • Revised 6 June 2019 • Accepted 26 June 2019 • Published online 3 September 2019

\section{Abstract:}

Objective: To evaluate the outcome of pregnant women with abnormal placentation who underwent transient hypogastric artery balloon occlusion with cesarean hysterectomy.

Material and Methods: Descriptive retrospective study of patients with abnormal adherent placenta who underwent transient hypogastric artery balloon occlusion with cesarean hysterectomy between January 2014 and December 2016. Data were recorded and analyzed.

Results: Fourteen pregnant women with abnormal placentation were included in our series. Most patients underwent cesarean hysterectomy at less than 37 weeks of gestational age. The sonograms of 7 cases overestimated the severity of placenta adherence compared with the pathological diagnosis. The median estimated blood loss was 4,350 milliliters ( $\mathrm{mL}$ ). The median estimated blood loss in placenta accrete, increta and percreta were 3,000 $\mathrm{mL}, 5,337$ $\mathrm{mL}$ and 5,150 $\mathrm{mL}$, respectively. One case had a procedure-related complication: perforation of the small branch of the anterior division of the right hypogastric artery from the guidewire.

Conclusion: Intraoperative transient balloon occlusion of the hypogastric arteries was an effective method and safe treatment for controlling the massive intraoperative bleeding of cesarean hysterectomy. This technique can be an alternative option in combination with surgery in cases of abnormal placental adherence.

Keywords: adherent placenta, cesarean hysterectomy, hypogastric artery, transient balloon occlusion

Contact: Asst. Prof. Keerati Hongsakul, M.D.

Department of Radiology, Faculty of Medicine, Prince of Songkla University,

Hat Yai, Songkhla 90110, Thailand.

E-mail: keeratihongsakul@yahoo.com
J Health Sci Med Res 2019;37(4):289-296 doi: 10.31584/jhsmr.201963 www.jhsmr.org 


\section{Introduction}

Morbidly adherent placenta is a general term that includes placenta accreta, increta and percreta. Placenta accreta refers to a condition in which the placental villi invades the superficial myometrium; placenta increta refers to the invasion of the myometrium by the placental villi; and, placenta percreta, the most severe form, refers to the villi tissue penetrating the full thickness of the myometrium and invading the uterine serosa or adjacent organs. ${ }^{1}$ Incidence of adherent placenta increases directly in correlation with a history of previous cesarean section. ${ }^{2}$ In these cases, the anatomy is frequently distorted, tissues are more friable, neovascularization is present, tissue planes are less defined, and massive hemorrhages are more likely. These factors worsen progressively with deeper placental invasion. The maternal mortality rate has been reported to be $7.0 \%{ }^{3}$

Nowadays, the rate of previous cesarean section continues to rise; thus, the incidence of abnormal adherent placenta has also increased. ${ }^{4}$ Treatment of adherent placenta is a hysterectomy. Several surgical techniques have been performed to minimize blood loss in these patients. Ligation of the internal iliac artery is one of the techniques used to control bleeding. However, the success rate to control bleeding is less than $50.0 \%$ due to the rapid recruitment of collateral vessels in the pelvic cavity. ${ }^{5-7}$

Due to the advancement of minimally invasive techniques in interventional radiology, the national guidelines of the $\mathrm{UK}^{8}$ recommend the use of interventional radiology with prophylactic placement of internal iliac artery balloon occlusion catheters to reduce intraoperative bleeding during caesarean section for women with abnormal placentation. Several studies have reported that temporary balloon occlusion is relatively safe and associated with a reduced estimated blood loss and fewer massive transfusions compared with groups without balloons. ${ }^{9-14}$ In contrast, some literature has reported no statistical difference in mean of estimated blood loss, volume of replaced blood products, fluid replacement needs, operating room time or postoperative recovery time between patients in balloon occlusion and non-balloon occlusion groups. ${ }^{4,15}$ Even though temporary balloon occlusion of the hypogastric artery is minimally invasive, there are reports of complications, including arterial occlusion, pseudoaneurysm, ruptured artery and dissection. ${ }^{16,17}$

In our hospital, which is the only tertiary hospital in Southern Thailand, we have performed transient hypogastric balloon occlusion adjunct with cesarean hysterectomy since 2014, in order to reduce maternal blood loss in pregnant women with abnormal adherent placenta. The objective of our study was to determine the outcome of transient hypogastric artery balloon occlusion with cesarean hysterectomy in abnormal adherent placenta.

\section{Material and Methods}

\section{Patients}

This was a retrospective study of all the pregnant women with imaging diagnosis of abnormal adherent placenta who underwent transient hypogastric balloon occlusion with cesarean hysterectomy in Songklanagarind Hospital between January 2014 and December 2016. The data were retrieved from interventional radiology records and the hospital database. Finally, 14 pregnant women were included. This study was approved by the Human Research Ethics Committees of our institution.

\section{Procedure}

Procedures were performed in the operating room. Patients were in the supine position. The skin and both inguinal areas were cleaned with antiseptic solution. Bilateral common femoral punctures were performed under ultrasound guidance and local anesthesia by lidocaine injection; then a 5 French $(\mathrm{Fr})$ vascular sheath was inserted in each side. Next, selection of each hypogastric artery was performed using Advantage guidewire (Terumo, Leuven, Belgium) and a 5-Fr internal mammary catheter using the contralateral approach under portable C-arm fluoroscopic 
guidance. Both catheters were removed; then a $6-\mathrm{mm}$ in diameter and 40-mm in length semi-compliant balloon catheter (Mustang, Boston Scientific Corporation, MA, USA) was inserted over the guidewire and placed at the common trunk of each hypogastric artery. The hub of each balloon catheter was connected to an inflator and the fixation of each balloon catheter was completed. Cesarean section was performed under general anesthesia. After the delivery of the neonate and the umbilical cord was clamped, the balloons were inflated to the nominal pressure (10 atmospheres) for 5 minutes (Figure 1) and then the pressure was decreased by 2 atmospheres every 10 minutes until it was down to 2 atmospheres, where it was maintained until the surgical procedure was finished. However, the pressure could be adjusted regardless of the severity of bleeding during the surgical procedure. After finishing the surgical procedure, balloons were deflated and removed followed by manual compression at both groins for hemostasis.

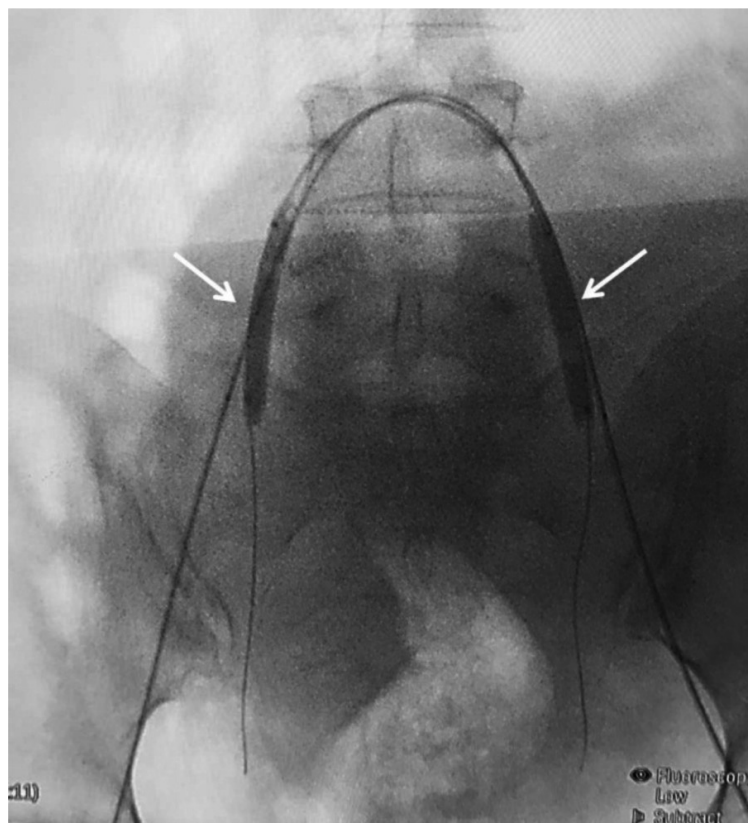

Figure 1 Radiography showing balloons (arrows) in bilateral hypogastric arteries

\section{Data evaluation and statistical analysis}

Data on patient demographics, obstetric history, laboratory and pathologic results, operative findings, and complications were obtained from the electronic medical record system and radiology information system database. The quantitative data were expressed as median (maximum, minimum), while the qualitative parameters were presented as counted numbers.

\section{Results}

The demographic data are shown in Table 1. The mean age was 35.3 years. Most patients (10 patients) underwent cesarean hysterectomy at less than 37 weeks of gestational age. One case (patient no. 13) had the lowest gestational age at 27 weeks 3 days, and the child was stillborn. Most cases (12 patients) had a history of previous cesarean section. When compared with pathological diagnosis, there were 7 cases in which the sonogram overestimated the severity of placenta adherence.

Summarization of the operative data of the patients is shown in Table 2. The median pre- and post-operative hematocrit levels were $35.2 \%$ and $31.0 \%$, respectively. The median estimated blood loss (EBL) was 4,350 mL. Median transfused packed red blood cells (PRBC) and fresh frozen plasma (FFP) were $1,060.5$ and $1,071 \mathrm{~mL}$. There was one case (patient no. 12) that did not receive PRBC or FFP.

Summarization and outcome of each group of placenta adherence are shown in Table 3. Most pregnant women in this study had placenta increta. There were 2 cases of diagnosed placenta adherence from prenatal sonogram; however, there was no placenta adherence from pathological diagnosis. The highest median estimated blood loss was found in the placenta increta group. Women with placenta increta in this study also received the most transfused PRBC and FFP.

The intra-operative complication of perforation of the small branch of the anterior division of the right hypo- 
gastric artery from the guidewire was found (patient no.

10). Ligation of the vessel was performed to correct this complication. There was no post-operative complication related to this interventional procedure.

Table 1 Demographic and obstetric data of the patients

\begin{tabular}{|c|c|c|c|c|c|c|c|}
\hline \multirow{2}{*}{$\begin{array}{l}\text { Patient } \\
\text { number }\end{array}$} & \multirow{2}{*}{ Age (year) } & \multirow{2}{*}{ Gravida } & \multicolumn{2}{|c|}{ Gestational age } & \multirow{2}{*}{ Previous $\mathrm{C} / \mathrm{S}$} & \multirow{2}{*}{$\begin{array}{l}\text { Prenatal } \\
\text { diagnosis }\end{array}$} & \multirow{2}{*}{$\begin{array}{l}\text { Pathologic } \\
\text { diagnosis }\end{array}$} \\
\hline & & & (week) & (day) & & & \\
\hline 1 & 38 & G3P1A1 & 34 & 5 & Yes & Percreta & Increta \\
\hline 2 & 30 & G2P1 & 33 & 3 & Yes & Increta & Accrete \\
\hline 3 & 39 & G3P2 & 35 & 5 & Yes & Increta & Increta \\
\hline 4 & 38 & G2P1 & 37 & 6 & No & Percreta & No \\
\hline 5 & 35 & G4P1A2 & 37 & 3 & No & Accrete & No \\
\hline 6 & 39 & G4P2A1 & 36 & 0 & Yes & Accrete & Increta \\
\hline 7 & 34 & G4P2A1 & 39 & 0 & Yes & Percreta & Increta \\
\hline 8 & 37 & G3P1A1 & 35 & 0 & Yes & Percreta & Percreta \\
\hline 9 & 27 & G3P2 & 37 & 2 & Yes & Percreta & Increta \\
\hline 10 & 40 & G5P4 & 34 & 1 & Yes & Increta & Percreta \\
\hline 11 & 33 & G3P2 & 36 & 5 & Yes & Increta & Increta \\
\hline 12 & 30 & G3P2 & 35 & 5 & Yes & Increta & Accrete \\
\hline 13 & 40 & G2P1 & 27 & 3 & Yes & Increta & Increta \\
\hline 14 & 34 & G6P2A3 & 33 & 3 & Yes & Increta & Increta \\
\hline
\end{tabular}

$\mathrm{G}=$ gravida, $\mathrm{P}=$ the outcome of those pregnancies, $\mathrm{A}=$ the abortion of those pregnancies, $\mathrm{C} / \mathrm{S}=\mathrm{cesarean}$ section

Table 2 Patients' operative data

\begin{tabular}{lllllll}
\hline Patients number & $\begin{array}{l}\text { Pre-operative } \\
\text { Hct }(\%)\end{array}$ & $\begin{array}{l}\text { Operative time } \\
(\mathbf{m i n})\end{array}$ & $\begin{array}{l}\text { Post-operative } \\
\text { Hct }(\%)\end{array}$ & EBL $(\mathbf{m L})$ & $\begin{array}{l}\text { Transfused } \\
\text { PRBC }(\mathbf{m L})\end{array}$ & $\begin{array}{l}\text { Transfused FFP } \\
(\mathbf{m L})\end{array}$ \\
\hline 1 & 30.4 & 255 & 30.9 & $6,000.0$ & 908.0 & $1,059.0$ \\
2 & 38.0 & 255 & 29.8 & $5,000.0$ & $1,033.0$ & $1,458.0$ \\
3 & 29.0 & 345 & 27.6 & $7,500.0$ & $2,002.0$ & $2,180.0$ \\
4 & 38.3 & 195 & 37.9 & $1,700.0$ & $1,031.0$ & 499.0 \\
5 & 35.0 & 315 & 30.2 & $1,500.0$ & 290.0 & 0.0 \\
6 & 36.1 & 235 & 31.1 & $3,000.0$ & 632.0 & $1,083.0$ \\
7 & 34.0 & 380 & 33.8 & $2,300.0$ & $1,545.0$ & $1,600.0$ \\
8 & 35.3 & 240 & 32.5 & $4,500.0$ & $1,150.0$ & 986.0 \\
9 & 31.3 & 335 & 28.0 & $4,200.0$ & $1,190.0$ & 850.0 \\
10 & 34.1 & 395 & 24.7 & $5,800.0$ & $1,551.0$ & $1,214.0$ \\
11 & 35.3 & 365 & 33.8 & $11,000.0$ & $4,605.0$ & $3,828.0$ \\
12 & 37.2 & 269 & 34.6 & $1,000.0$ & 0.0 & 0.0 \\
13 & 31.5 & 245 & 27.9 & $5,000.0$ & $1,088.0$ & $1,685.0$ \\
14 & 36.8 & 225 & 34.6 & $3,700.0$ & 855.0 & 626.0 \\
Median & 35.2 & 262 & 31.0 & $4,350.0$ & $1,060.5$ & $1,071.0$ \\
\hline
\end{tabular}

Hct=Hematocrit, EBL=estimated blood loss, $\mathrm{PRBC}=$ packed red blood cells, FFP=fresh frozen plasm 
Table 3 Characteristics and outcomes in each group of abnormal placental adherence based on pathological diagnosis

\begin{tabular}{lllll}
\hline Characteristics & $\begin{array}{l}\text { Patients without } \\
\text { abnormal adherence } \\
(\mathbf{n = 2})\end{array}$ & $\begin{array}{l}\text { Patients with } \\
\text { placenta accreta } \\
(\mathbf{n = 2})\end{array}$ & $\begin{array}{l}\text { Patients with } \\
\text { placenta increta } \\
(\mathbf{n = 8})\end{array}$ & $\begin{array}{l}\text { Patients with } \\
\text { placenta percreta } \\
(\mathbf{n = 2})\end{array}$ \\
\hline Age (years) & 36.5 & 30.0 & 35.5 & 38.5 \\
Gestational age (week) & 37.0 & 34.0 & 35.0 & 35.0 \\
Estimate blood loss $(\mathrm{mL})$ & $1,600.0$ & $3,000.0$ & $5,337.0$ & $5,150.0$ \\
(min, max) & $(1,500,1,700)$ & $(1,000,5,000)$ & $(2,300,11,000)$ & $(4,500,5,800)$ \\
Transfused PRBC $(\mathrm{mL})$ & 660.5 & 516.5 & $1,603.1$ & 1350.5 \\
Transfused FFP $(\mathrm{mL})$ & 249.5 & 729.0 & $1,613.8$ & $1,100.0$ \\
Decreased Hct level $(\%)^{*}$ & 2.6 & 5.4 & 2.1 & 6.1 \\
\hline
\end{tabular}

*pre-operative hematocrit subtract with post-operative hematocrit

PRBC=packed red blood cell, FFP=fresh frozen plasma, Hct=hematocrit, min=minimum, max=maximum

\section{Discussion}

For the evaluation of the degree of placental invasion, ultrasound can overestimate the diagnosis compared with the pathological method. The median EBL of the combination of transient balloon occlusion in hypogastric arteries and cesarean hysterectomy in this study was $4,350 \mathrm{~mL}$. Placenta increta was the most common type of blood loss in our series. We found one case with a complication that was related to the procedure.

Sonogram is widely accepted to be the primary modality for prenatal diagnosis and exclusion of abnormal placentation because it is highly accurate, does not expose the patient to radiation, and inexpensive. ${ }^{18}$ Results from a systematic review and meta-analysis of the diagnosis of abnormal placentation by ultrasound showed an 81.0-91.0\% sensitivity, 95.0-99.0\% specificity, 65.0-93.0\% positive predictive value, and a $98.0 \%$ negative predictive value. ${ }^{19,20}$ However, ultrasound might overestimate the severity of placental invasion as found in $50.0 \%$ of the cases in our series. The reasons may be affected by bias due to the inclusion of a single expert, prior knowledge of patients' risk factors, and a wide variability of definitions on the placenta accreta spectrum. ${ }^{21}$ Additionally, an ultrasound is operator dependent, and thus outcome is related to the skill and experience of the operator. Magnetic resonance image (MRI) has a role in the diagnosis of adherent placenta when the sonogram evaluation is equivocal. ${ }^{22}$ In cases in which the diagnosis by sonogram is definitive, MRI is used to plan for surgery, especially for the evaluation of the invasion of any adjacent organs in case of placenta percreta. $^{22}$ There were 4 pregnant women in this study who underwent $\mathrm{MRI}$ to evaluate adherent placenta because of an equivocal sonogram result. However, the results were not different than their previous sonograms.

Several studies have reported that the preoperative placement of temporary balloon occlusion is relatively safe and associated with a reduced estimated blood loss and fewer massive transfusions compared with a group without balloon occlusions for the cesarean hysterectomy. ${ }^{9-14}$ A study by Miller et al. ${ }^{23}$ reported that blood loss during cesarean hysterectomy without temporary balloon occlusion in 62 pregnant women with adherent placentas was between 2,000 to $20,000 \mathrm{~mL}$, whereas blood loss in this study ranged from 1,000 to $11,000 \mathrm{~mL}$. The mean $\mathrm{EBL}$ in our 
study was $4,350 \mathrm{~mL}$, which was higher than several studies that used temporary balloon occlusion ${ }^{9-14}$ showing mean EBL ranging from 800 to $2,800 \mathrm{~mL}$. The reason may be that most of the subjects in our study were pregnant women with placenta increta and percreta, whereas in previous studies $^{9-14}$ they were pregnant women with placenta accreta, which is less severe. Moreover, a few studies ${ }^{4,15}$ performed the combination of embolization of the bilateral hypogastric arteries to reduce pelvic circulation. In our study, however, combined embolization was not performed because we were concerned about increasing pelvic ischemia and the length of the operation. A study by Chou et al. ${ }^{24}$ reported the EBL in 13 pregnant women with adherent placenta; most subjects in their study had placenta increta and percreta, which is similar to our study. Mean intraoperative blood loss was 1,902.3 $\pm 578.8 \mathrm{~mL}$ (range 500-8,000 mL), which was less than in our study. The temporary balloon occlusions in their study were performed at the level of the bilateral common iliac arteries because they believed this technique had more definitive devascularization. However, this technique is high risk for acute limb ischemia due to distal emboli to popliteal artery and acute thrombosis of the external iliac artery. ${ }^{24}$ Additionally, the overall gestational age at cesarean hysterectomy in the study of Chou et al. ${ }^{24}$ was less than our study (median 30.5 weeks, ranging from 19 to 36 weeks) and therefore intraoperative blood loss might have been lower. Even though most of the literature indicated that temporary balloon occlusion showed a good result for decreasing the EBL from cesarean hysterectomy, there were a few studies that showed no statistically significant difference in blood loss between the using and non-using balloon occlusion groups. ${ }^{4,15}$ Additionally, there was no statistical significance in volume of replaced blood products, fluid replacement needs, operating room time, or postoperative recovery time. ${ }^{4,15}$
The main risk of bleeding during surgery depends on the severity of the invasive placenta. The most severe placental invasion is placenta percreta due to much collateral arterial supply; thus, it is the cause of a high chance of bleeding during the operation. However, in this series, the group with the most blood loss was women with placenta increta because they were the majority of the population in this study, whereas we had only 2 cases of placenta percreta. The variety of obstetric doctors performing cesarean hysterectomy in our hospital was another factor related to blood loss, varying according to experience, skill and technique.

Most case series and case reports declared that balloon occlusion was safe and had a low morbidity; however, complications from balloon occlusion have been reported. The study by Carnevale et al. ${ }^{14}$ presented 2 of 21 cases that had acute ilio-femoral occlusion due to long operations. Both of these cases were treated by embolectomy. Another case report by Sewell et al. ${ }^{25}$ also described acute popliteal occlusion requiring embolectomy. Other complications related to the procedures that were reported include pseudoaneurysm, ruptured artery, and dissection. ${ }^{16,17}$ Our series found one case of a guidewire penetrating from a small branch of the anterior division of the right hypogastric artery into the pelvic cavity. It was treated by ligation. We suspect the cause may have been the deep position of the tip of the guidewire into the aforementioned branch. There was no procedural related acute ilio-femoral or popliteal occlusion in our series, which is similar to previous studies. ${ }^{16,17}$

Temporary balloon occlusion is a feasible technique for cesarean hysterectomy. This technique is not difficult and can be performed under $\mathrm{C}$-arm fluoroscopic guidance in the operating theater before cesarean hysterectomy. Practically, the duration of balloon catheter placements at the bilateral hypogastric arteries does not exceed 30 minutes. Two important factors of the procedures are the 
proper position of balloon placement and the appropriate size of balloon catheter for effective devascularization and reducing complications. The proper position of the balloon must be in common with the hypogastric artery and can be located by using the bony landmark; the upper end of the balloon should be located at the lower endplate of the L4 vertebra. The size of the balloon should not exceed $6 \mathrm{~mm}$ in diameter and 20 to $40 \mathrm{~mm}$ in length. In our opinion, this technique can be performed as an adjunct procedure to cesarean hysterectomy in cases of pregnancy with adherent placenta, particularly placenta increta and percreta.

This study had some limitations. Firstly, it was a retrospective study with a small number of enrolled patients. Secondly, the decision whether or not to perform balloon occlusion before cesarean hysterectomy depended on discussions between obstetric doctors, which might have been a cause of selection bias. Lastly, the effect of radiation exposure to the neonate was not determined because we used a portable $\mathrm{C}$-arm fluoroscopic X-ray system that could not record the radiation dose.

\section{Conclusion}

Abnormal adherent placenta is a serious obstetric condition that can lead to maternal morbidity. Our case series showed that transient hypogastric artery balloon occlusion with cesarean hysterectomy was an effective method and safe treatment for controlling massive intraoperative bleeding. This technique can be an alternative option in combination with surgery for treating pregnant women with abnormal adherent placenta.

\section{Acknowledgement}

The authors thank Trevor Pearson of the International Affairs Office, Faculty of Medicine, Prince of Songkla University for editing the English.

\section{Conflict of interest}

There are no potential conflict of interest to declare.

\section{References}

1. Bailit JL, Grobman W, Rice MM, Reddy UM, Wapner RJ, Varner MW, et al. Morbidly adherent placenta treatments and outcomes. Obstet Gynecol 2015;125:683-9.

2. Silver RM, Landon MB, Rouse DJ, Leveno KJ, Spong CY, Thom EA. Maternal morbidity associated with multiple repeat cesarean deliveries. Obstet Gynecol 2006;107:1226-32.

3. Eller AG, Porter TF, Soisson P, Silver RM. Optimal management strategies for placenta accreta. BJOG 2009;116:648-54.

4. Bodner LJ, Nosher JL, Gribbin C, Siegel RL, Beale S, Scorza W. Balloon-assisted occlusion of the internal iliac arteries in patients with placenta accreta/percreta. Cardiovasc Intervent Radiol 2006;29:354-61.

5. Clark SL, Phelan JP, Yeh SY, Bruce SR, Paul RH. Hypogastric artery ligation for obstetric hemorrhage. Obstet Gynecol 1985; 66:353-6.

6. Evans S, McShane P. The efficacy of internal iliac artery ligation in obstetric hemorrhage. Surg Gynecol Obstet 1985;160: 250-3.

7. Chait A, Moltz A, Nelson JH Jr. The collateral arterial circulation in the pelvis: an angiographic study. Am $\mathrm{J}$ Roentgenol Radium Ther Nucl Med 1968;102:392-400.

8. Royal College of Obstetricians and Gynaecologists, Royal College of Radiologists, British Society of Interventional Radiology. Good Practice No. 6: The role of emergency and elective interventional radiology in postpartum haemorrhage [monograph on the Internet]. London: RCOG, RCR, BSIR; 2007 [cited 2017 Apr 23]. Available from: https://www.rcog.org.uk/ globalassets/documents/guidelines/goodpractice6role emergency2007.pdf

9. Ballas J, Hull AD, Saenz C, Warshak CR, Roberts AC, Resnik $\mathrm{RR}$, et al. Preoperative intravascular balloon catheters and surgical outcomes in pregnancies complicated by placenta accreta: a management paradox. Am J Obstet Gynecol 2012; 207:216.e1-5.

10. Yi KW, Oh MJ, Seo TS, So KA, Paek YC, Kim HJ. Prophylactic hypogastric artery ballooning in a patient with complete placenta previa and increta. J Korean Med Sci 2010;25:651-5. 
11. Darwish HS, Zaytoun HA. Kamel HA, Habash YH. Prophylactic preoperative balloon occlusion of hypogastric arteries in abnormal placentation; 5 years experience. Egypt $\mathrm{J}$ Radiol Nucl Med 2014;45:751-9.

12. Cali G, Forlani F, Giambanco L, Amico ML, Vallone M, Puccio G, et al. Prophylactic use of intravascular balloon catheters in women with placenta accreta, increta and percreta. Eur J Obstet Gynecol Reprod Biol 2014;179:36-41.

13. Tan CH, Tay KH, Sheah K, Kwek K, Wong K, Tan HK, et al. Perioperative endovascular internal iliac artery occlusion balloon placement in management of placenta accrete. AJR Am J Roentgenol 2007;189:1158-63.

14. Carnevale FC, Kondo MM, de Oliveira Sousa W Jr, Santos AB, da Motta Leal Filho JM, Moreira AM, et al. Perioperative temporary occlusion of the internal iliac arteries as prophylaxis in cesarean section at risk of hemorrhage in placenta accreta. Cardiovasc Intervent Radiol 2011;34:758-64.

15. Salim R, Chulski A, Romano S, Garmi G, Rudin M, Shalev E. Precesarean prophylactic balloon catheters for suspected placenta accreta: a randomized controlled trial. Obstet Gynecol 2015;126:1022-8.

16. Bishop S, Butler K, Monaghan S, Chan K, Murphy G, Edozien L. Multiple complications following the use of prophylactic internal iliac artery balloon catheterization in a patient with placenta percreta. Int J Obstet Anesth 2011;20:70-3.

17. Manalo EP, Barker AE. Histopathologic findings in human aortic media associated with pregnancy. Arch Pathol 1967; 83:336-41.

18. Pagani G, Cali G, Acharya G, Trisch IT, Palacios-Jaraquemada
$\mathrm{J}$, Familiari A. et al. Diagnostic accuracy of ultrasound in detecting the severity of abnormally invasive placentation: a systematic review and meta-analysis. Acta Obstet Gynecol Scand 2018;97:25-37.

19. Philips J, Abuhamad A. Diagnosing placenta accreta spectrum with prenatal ultrasound. OBG Manag 2018;30:34-44.

20. Bowman ZS, Eller AG, Kennedy AM, Richards DS, Winter TC, Woodward PJ, et al. Accuracy of ultrasound for the prediction of placenta accreta. Am J Obstet Gynecol 2014;211:177.e1-7.

21. Rac MW, Moschos E, Wells CE, Mclntire DD, Dashe JS, Twickler DM. Sonographic findings of morbidly adherent placenta in the first trimester. J Ultrasound Med 2016;35: 263-9.

22. Kilcoyne A, Shenoy-Bhangle AS, Roberts DJ, Sisodia RC, Gervais DA, Lee SI. MRI of placenta accreta, placenta increta, and placenta percreta: pearls and pitfalls. AJR Am J Roentgenol 2017;208:214-21.

23. Miller DA, Chollet JA, Goodwin TM. Clinical risk factors for placenta previa-placenta accreta. Am J Obstet Gynecol 1997;177:210-4.

24. Chou MM, Kung HF, Hwang JI, Chen WC, Tseng JJ. Temporary prophylactic intravascular balloon occlusion of the common iliac arteries before cesarean hysterectomy for controlling operative blood loss in abnormal placentation. Taiwan $\mathrm{J}$ Obstet Gynecol 2015;54:493-8.

25. Sewell MF, Rosenblum D, Ehrenberg H. Arterial embolus during common iliac balloon catheterization at cesarean hysterectomy. Obstet Gynecol 2006;108:746-8. 